\title{
Identified Primary Motoneurons in Embryonic Zebrafish Select Appropriate Pathways in the Absence of Other Primary Motoneurons
}

\author{
Susan H. Pike and Judith S. Eisen \\ Institute of Neuroscience, University of Oregon, Eugene, Oregon 97403
}

\begin{abstract}
Accurate pathfinding is a crucial step in formation of a functional nervous system. Individually identified zebrafish primary motoneurons undergo a stereotyped temporal sequence of axonal outgrowth and pathway selection during which their growth cones follow a common pathway to a "choice point" and then select divergent cell-specific pathways that lead to separate muscle territories. The characteristic sequence of cell-specific pathway selection raises the possibility that the sequence of growth cone arrival at the choice point might determine pathway selection. To test this idea, we ablated identified primary motoneurons by laser irradiation, labeled the remaining primary motoneuron in the same hemisegment with a fluorescent dye, and followed its development through the end of embryogenesis. We found that the growth cone of each primary motoneuron has an independent ability to pioneer the common pathway and select its appropriate cell-specific pathway, even in the absence of all other primary motoneurons in the same hemisegment.
\end{abstract}

Formation of a functional nervous system requires that the growth cones of developing neurons establish synaptic connections with appropriate target cells. Recent studies in a variety of systems suggest that growth cones do not extend randomly, but rather select specific pathways leading directly to appropriate targets (Landmesser, 1980; Goodman et al., 1982; Myers et al., 1986; Davies, 1987). During pathfinding, the growth cones of different types of neurons make different choices when confronted with the same environment (Bastiani and Goodman, 1984; Kapfhammer and Raper, 1987), implying heterogeneity of the environment, the neurons, or both. Furthermore, an individual growth cone may exhibit affinities for different environmental cues at different stages of pathway navigation (Berlot and Goodman, 1984; Caudy and Bentley, 1986a, b; Bastiani et al., 1987; see also Dodd et al., 1988). We have used the relatively simple zebrafish embryo as a system for studying pathfinding because the development of individual neurons can be observed in vivo. Studies of pathfinding by identified motoneurons in zebrafish embryos show that although these neurons are of the

\footnotetext{
Received Mar. 8, 1989; revised June 13, 1989; accepted June 26, 1989

We thank Sumita Ray, Babette Romancier, Harry Howard, Sean Poston, and Ed Sullivan for technical assistance; Bettina Debu, Charles Kimmel, Peter O'Day, Paul Myers, Eric Hanneman, Diane Sepich, Greg Bobrowicz, and Monte Westerfield for criticism of the manuscript; and our colleagues in the Institute of Neuroscience for discussions of these results. Supported by NS23915, BNS8553146, the Procter and Gamble Company, the Murdock Charitable Trust, a Searle Scholar Award to J.S.E., and a Patricia Roberts Harris Fellowship to S.H.P.

Correspondence should be addressed to Judith $\mathrm{S}$. Eisen at the above address. Copyright (C) 1990 Society for Neuroscience $0270-6474 / 90 / 010044-06 \$ 02.00 / 0$
}

same type, they make different pathway choices when confronted with the same environment (Eisen et al., 1986; Myers et al., 1986). In addition, the growth cones of these cells may exhibit affinities for different environmental cues at different stages of pathway navigation (B. Debu and J. S. Eisen, unpublished observations).

Each side of every trunk segment in the embryonic zebrafish is innervated by a set of identified motoneurons, the primary motoneurons (Myers, 1985; Westerfield et al., 1986), which exhibit a stereotyped temporal sequence of axonal outgrowth and pathway selection in which $\mathrm{CaP}$ precedes $\mathrm{MiP}$ and $\mathrm{MiP}$ precedes RoP (Eisen et al., 1986; Myers et al., 1986). In some segments, an additional primary motoneuron called $\mathrm{VaP}$ is also present, but its presence does not appear to affect pathfinding by the other primary motoneurons (Eisen et al., 1990). CaP pioneers a common pathway to a "choice point" where the growth cones of all of the primary motoneurons pause. After pausing, each growth cone, in turn, selects a different cell-specific pathway that leads to an exclusive muscle territory; the CaP growth cone selects a ventral pathway, the MiP growth cone selects a dorsal pathway, and the RoP growth cone selects a lateral pathway.

The stereotyped sequence of cell-specific pathway selection by the growth cones of the primary motoneurons suggests that their order of arrival at the choice point might be important for determining growth cone pathway selection. One prediction of this hypothesis is that the first growth cone to arrive at the choice point will always select the ventral pathway. We previously tested this idea by ablating $\mathrm{CaP}$ and examining pathway selection by the MiP growth cone over the next several hours (Eisen et al., 1989, 1990). We found that initially the MiP growth cone did not select the ventral pathway. However, all of the MiPs examined through $24 \mathrm{~h}$ retained a ventral process in contact with the region of the choice point. This contrasts with MiPs observed in earlier studies, most of which had retracted their ventral processes by $24 \mathrm{~h}$ (Eisen et al., 1986; Myers et al., 1986). This observation raised the possibility that at later developmental stages the MiP growth cone might extend along the vacant ventral pathway into CaP territory. Moreover, previous studies did not examine whether the RoP growth cone might select the vacant ventral pathway in the absence of $\mathrm{CaP}$.

In the present study we ablated various combinations of primary motoneurons within a single hemisegment and examined the pathways selected by the remaining primary motoneuron. We found that ablation of all but one of the primary motoneurons does not alter the pathway initially selected by the growth cone of that cell. Furthermore, we examined these cells through the end of embryonic development and observed that they did not extend processes along vacant motor pathways at later de- 

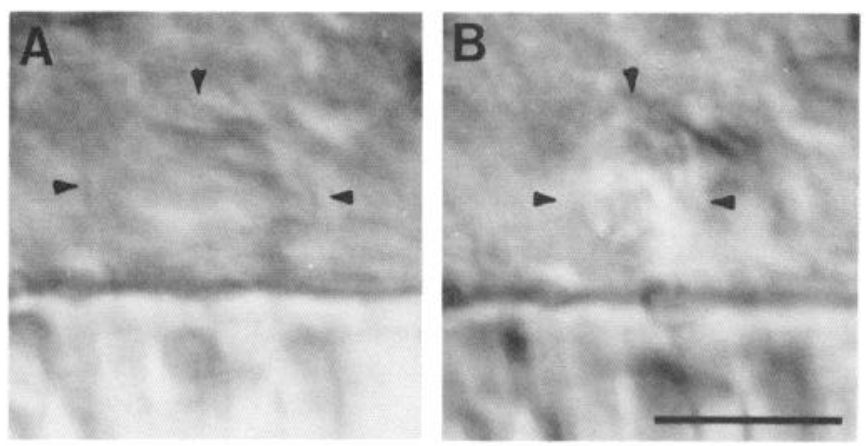

Figure 1. CaP dies following laser irradiation. $A$, Nomarski photomicrograph showing a CaP motoneuron (arrowheads) at $15 \mathrm{~h}$. B. The same CaP motoneuron (arrowheads) following laser irradiation. See text for a description of the criteria confirming that irradiated cells died. Scale bar, $10 \mu \mathrm{m}$.

velopmental times. We conclude that the sequence of arrival of the primary motor growth cones at the choice point does not dictate which pathway an individual growth cone selects. Some of these results have appeared in abstract form (Pike and Eisen, 1988).

\section{Materials and Methods}

Animals. Embryos of the zebrafish, Brachydanio rerio, were obtained from our laboratory colony and maintained as described in Myers et al. (1986). Embryos were staged by hours postfertilization at $28.5^{\circ} \mathrm{C}(\mathrm{h})$. Segments were numbered as described in Hanneman et al. (1988). A hemisegment refers to a single myotome plus the adjacent region of the spinal segment.

Chronic labeling. Individual motoneurons were labeled either by injection of the precursor blastomere with the lineage tracer, rhodamine dextran as described in Kimmel and Law (1985) and Eisen et al. (1986), or extracellular application of the fluorescent lipid-soluble dye, $1,1^{\prime}$ dioctadecyl-3,3,3',3'-tetramethylindocarbocyanine perchlorate (Di-I Honig and Hume, 1986) to the cell body, as described in Eisen et al. (1990). The use of these dyes enabled us to make multiple observations of the same cell over the period of a few days. In order to maximize the number of motoneurons labeled with rhodamine dextran, we injected blastomeres located $75 \%$ of the distance from the animal pole to the margin. The injections were typically performed in blastulae containing approximately 1000 cells, along the plane defined by the second cleavage. Injections at this location yield more clones containing primary motoneurons than injections in other regions of the blastula (C. B. Kimmel, R. M. Warga, and T. S. Schilling, unpublished observations). Observations of labeled cells were made on a Zeiss Universal microscope equipped with epifluorescence illumination and Nomarski optics. A CCD array camera (Pulnix), coupled to a Dark Invader image intensifier (Meyers), was used to amplify the fluorescence to visible levels and transmit the image to a video cassette recorder (Gyyr) and highresolution video monitor (Lenco).

Acute labeling. Individual primary motoneurons were labeled for acute observation by intracellular iontophoresis of Lucifer yellow as described in Eisen et al. (1989). Labeling cells intracellularly typically killed the labeled cell within minutes of dye injection.

Ablations. Individual primary motoneurons were ablated by laser irradiation, as described in Eisen et al. (1989). The somata of all the primary motoneurons cannot always be unequivocally identified at the same stage of embryonic development. Therefore, to ablate more than one primary motoneuron in a hemisegment, we performed the ablations at several developmental stages. Embryos were mounted and ablations performed sequentially. $\mathrm{CaP}$, or $\mathrm{CaP}$ and $\mathrm{VaP}$, were typically visible by $15 \mathrm{~h}$, which is approximately $1-2 \mathrm{~h}$ prior to axogenesis. MiP was typically obvious at $17-18 \mathrm{~h}$, and RoP was typically obvious at $18-19 \mathrm{~h}$ $\mathrm{CaP}$ ablations were always performed prior to axogenesis (see Eisen et al., 1989). Determining the actual time of axogenesis for unlabeled MiPs and RoPs was often difficult because we could not discern the growth cone using Nomarski optics. From studies in which we labeled cells with $\mathrm{Di}-\mathrm{I}$, we determined that $\mathrm{MiP}$ growth cones typically leave
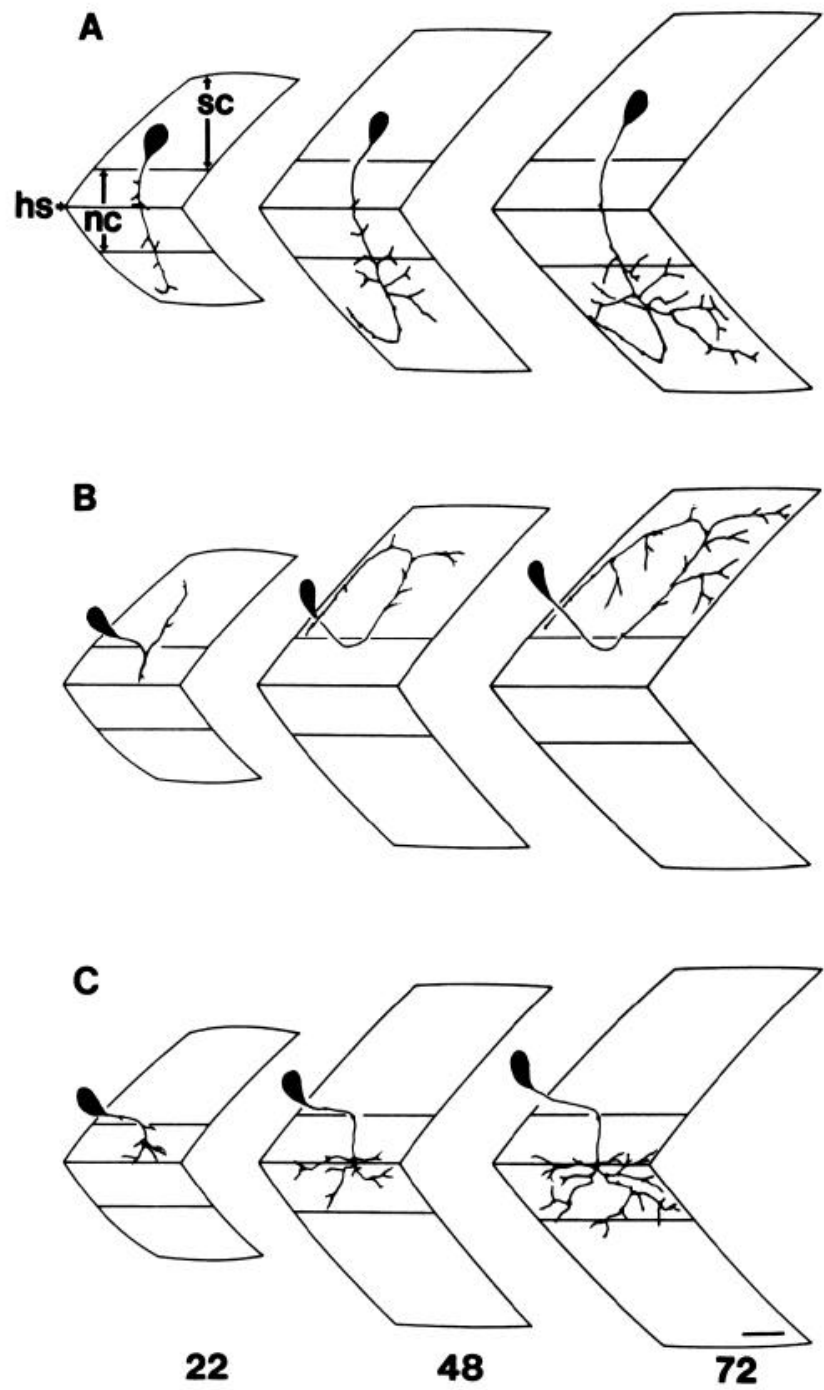

Figure 2. Normal outgrowth of primary motoneurons. The growth cone of each primary motoneuron grew directly to its appropriate muscle territory. Between 48-72 h, each motoneuron arborized extensively within its cell-specific territory. $A, \mathrm{~A}$ MiP motoneuron at 22,48 , and $72 \mathrm{~h} . \mathrm{B}, \mathrm{A}$ RoP motoneuron at 22,48 , and $72 \mathrm{~h}$. $C$, A CaP motoneuron at 22,48 , and $72 \mathrm{~h}$. Motoneurons were labeled with Di-I, axonal outgrowth monitored using video-enhanced microscopy, and the video signal recorded on tape. The cells shown here were drawn from the face of a video monitor. For this and subsequent figures, the outline of hemisegment 10 on the right side of an embryo was drawn to scale at 22,48 , and $72 \mathrm{~h}$ from the face of the video monitor, and the drawing of each motoneuron was superimposed on the standardized hemisegment outline. In this and subsequent figures, rostral is to the left and dorsal is to the top. Abbreviations: $s c$, spinal cord; $n c$, notochord; $h s$, horizontal septum. Scale bar, $20 \mu \mathrm{m}$.

the spinal cord between 18 and 19 h ( 9 out of 10 observations); RoP growth cones typically do so between 20 and 21 h ( 8 out of 10 observations). Ablations of MiP were performed prior to $18 \mathrm{~h}$ and ablations of RoP before $20 \mathrm{~h}$. We cannot be certain that all MiP and RoP ablations were performed prior to axogenesis, but the majority were. All ablations and observations were carried out in segments $8-15$. These segments were chosen because (1) primary motoneurons in segments rostral to 8 are difficult to label with Di-I because of the electrode configuration we use, and (2) we have not previously studied the normal development of primary motoneurons in segments caudal to segment 15 .

We employed 3 criteria to ascertain that the laser-irradiated cell had actually died. First, after irradiation, we observed the cell body swell and rupture (Fig. 1); this generally occurred within $5 \mathrm{~min}$ of irradiation. 

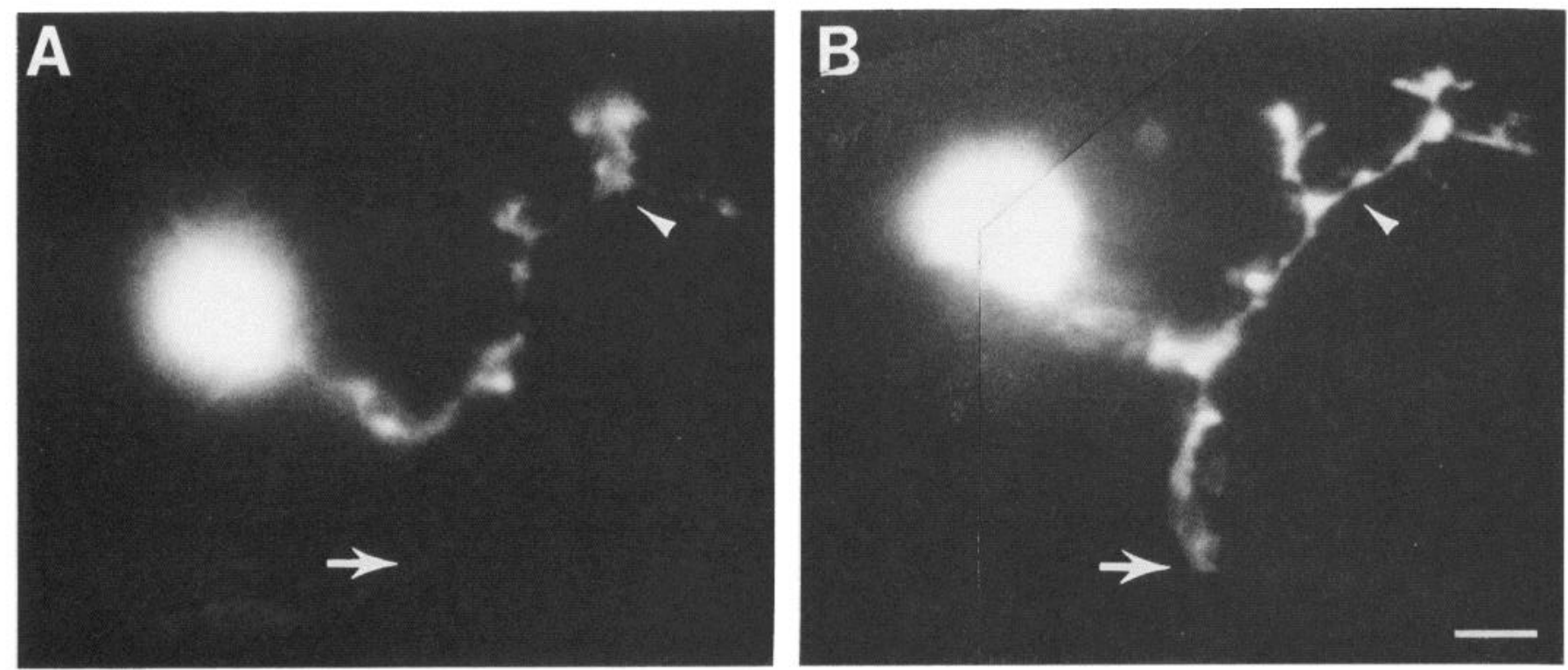

Figure 3. The time course of MiP ventral branch retraction is altered by CaP ablation. $A$, Fluorescence photomicrograph of a $24 \mathrm{~h}$ MiP labeled with Lucifer yellow in a control segment, in which $\mathrm{CaP}$ was present. This MiP had already retracted the ventral process from the horizontal septum (arrow) and had extended a process into the dorsal muscle (arrowhead). B. Fluorescence photomicrograph of a $24 \mathrm{~h} \mathrm{MiP} \mathrm{labeled} \mathrm{with} \mathrm{Lucifer} \mathrm{yellow}$ in a segment in which $\mathrm{CaP}$ and VaP had been ablated $9 \mathrm{~h}$ previously. This MiP still had a ventral process that extended to the horizontal septum (arrow) and also had extended a process into the dorsal muscle (arrowhead). Scale bar, $10 \mu \mathrm{m}$.

Second, at the time that we labeled a primary motoneuron for chronic observation in a hemisegment in which other primary motoneurons had been ablated, we carefully examined the spinal cord in that hemisegment using Nomarski optics to verify that the cell we had previously ablated was absent. Third, in 29 hemisegments in which primary motoneurons had been ablated, we labeled all of the remaining primary motoneurons with Lucifer yellow and confirmed that the cell we ablated was, indeed, absent.

\section{Results}

Pathway selection in normal embryos

Figure 2 illustrates the normal outgrowth of CaP, MiP, and RoP at 3 different time points, 22,48 , and $72 \mathrm{~h}$. Our observations corroborate previous work (Eisen et al., 1986), which showed that following axogenesis, each of the 3 primary motor growth cones extends unerringly to the specific region of muscle appropriate for its adult function (Westerfield et al., 1986).

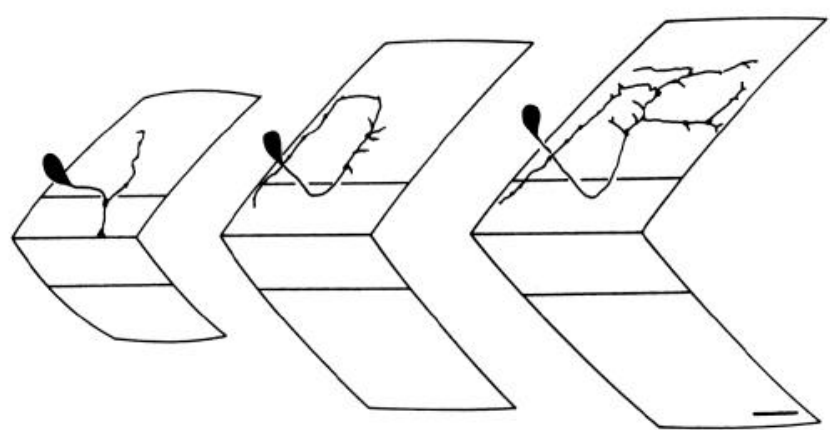

Figure 4. MiP arborizes in its normal cell-specific territory in the absence of $\mathrm{CaP}$. CaP was ablated prior to axogenesis, MiP labeled with $\mathrm{Di}-\mathrm{I}$ at $20 \mathrm{~h}$ and its development followed through $72 \mathrm{~h}$. MiP is shown at 22,48 , and $72 \mathrm{~h}$. Scale bar, $20 \mu \mathrm{m}$.
Pathway selection following primary motoneuron ablation Outgrowth of MiP

$\mathrm{CaP}, \mathrm{VaP}$, and RoP each extend a single axonal process that grows directly to its functionally appropriate muscle region (Eisen et al., 1986, 1989; Westerfield et al., 1986). Normal axonal outgrowth of MiP differs from that of the other primary motoneurons in that the ventral process that MiP extends to the horizontal septum retracts after a variable length of time and a more proximal collateral extends dorsally (Eisen et al., 1986). Previous studies showed that most MiPs had retracted their ventral processes by $24 \mathrm{~h}$ (Eisen et al., 1986; Myers et al., 1986). We corroborated this observation by labeling MiPs in segments containing $\mathrm{CaP}$, or $\mathrm{CaP}$ and $\mathrm{VaP}$, and determined that $75 \%$ of the MiPs had retracted the ventral process by $23-26 \mathrm{~h}$ (18 of 24; Fig. 3A). However, we found that, following $\mathrm{CaP}$ ablation, only $16 \%$ of the MiPs (4 of 25$)$ had retracted their ventral processes by $23-26 \mathrm{~h}$ (Fig. $3 B$ ).

The persistence of the MiP ventral process following $\mathrm{CaP}$ ablation raised the possibility that the MiP ventral process might extend along CaP's cell-specific pathway. Previous work showed that following ablation of $\mathrm{CaP}$ the MiP ventral process had not extended along the CaP pathway by $24 \mathrm{~h}$ (Eisen et al., 1989). However, since the ventral process was still present in all of these cases $(n=12)$, it was possible that, at a later time, process could still extend along the vacant $\mathrm{CaP}$ pathway. To test this possibility, we ablated $\mathrm{CaP}$ prior to axogenesis, labeled $\mathrm{MiP}$ with Di-I at $20 \mathrm{~h}$, and examined the outgrowth of MiP through the end of the embryonic period. In 5 out of 6 cases, the ventral process had been retracted by $48 \mathrm{~h}$. In one case, the ventral process persisted through $48 \mathrm{~h}$ but did not elaborate any noticeable branches or extend into CaP territory. Of $4 \mathrm{MiPs}$ followed through $72 \mathrm{~h}$, all had retracted their ventral process (Fig. 4). Moreover, these cells had arbors that were indistinguishable from MiP arbors in segments containing CaPs (see Fig. 2). Thus, 

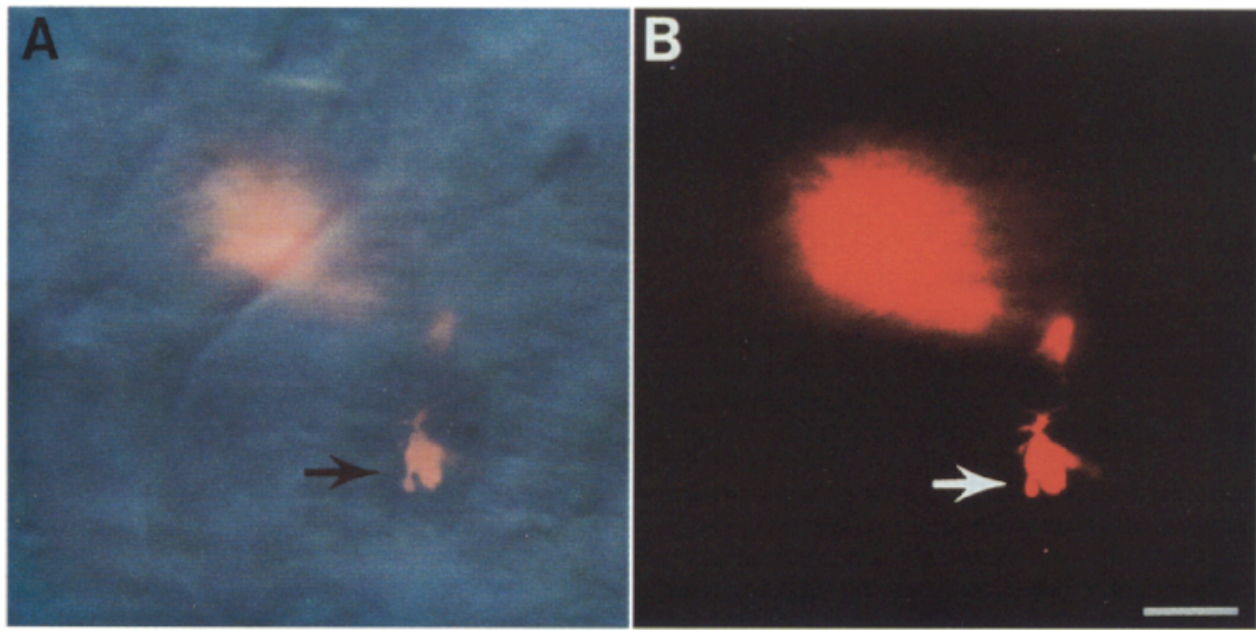

Figure 5. The RoP growth cone pioneers the common pathway in the absence of other primary motoneurons. $A$, Combination fluorescence and Nomarski photomicrograph of a Di-I-labeled $\mathrm{RoP}$ at $22 \mathrm{~h}$. The CaP, $\mathrm{VaP}$, and $\mathrm{MiP}$ in this hemisegment were ablated at 15 $\mathrm{h}(\mathrm{CaP}$ and $\mathrm{VaP})$ and $17 \mathrm{~h}(\mathrm{MiP})$. The RoP growth cone has left the spinal cord at the appropriate location and extended to the horizontal septum (arrow). B, The same cell photographed using only fluorescence optics. Scale bar, $10 \mu \mathrm{m}$.

in the absence of $\mathrm{CaP}$, MiP did not extend processes into $\mathrm{CaP}$ territory.

\section{Outgrowth of RoP}

Pioneering the common pathway. Previous results showed that the $\mathrm{CaP}, \mathrm{MiP}$, and $\mathrm{VaP}$ growth cones each have the ability to exit the spinal cord independently at the correct location and pioneer the common pathway to the horizontal septum (Eisen et al., 1989, 1990). To determine whether the growth cone of $\mathrm{RoP}$ is also able to exit the spinal cord at the appropriate place and pioneer the common pathway to the horizontal septum, we ablated all of the primary motoneurons caudal to RoP (either $\mathrm{CaP}$ and $\mathrm{MiP}$, or $\mathrm{CaP}, \mathrm{VaP}$, and $\mathrm{MiP}$ ) and examined the subsequent behavior of the RoP growth cone. In 9 of 9 cases, we found that following ablation of the other primary motoneurons, the RoP growth cone left the spinal cord at the normal location and pioneered the common pathway to the horizontal septum (Fig. 5). These results provide evidence that, like the other primary motoneurons, the RoP growth cone has an independent ability to exit the spinal cord and extend along the common pathway.

Selecting a cell-specific pathway. To test whether the RoP growth cone can select its normal cell-specific pathway in the absence of other primary motoneurons, we ablated $\mathrm{CaP}$ and $\mathrm{MiP}$ in segments in which $\mathrm{VaP}$ was not present $(n=3)$ or $\mathrm{CaP}$, $\mathrm{VaP}$, and $\mathrm{MiP}(n=2)$ and observed the subsequent pathway

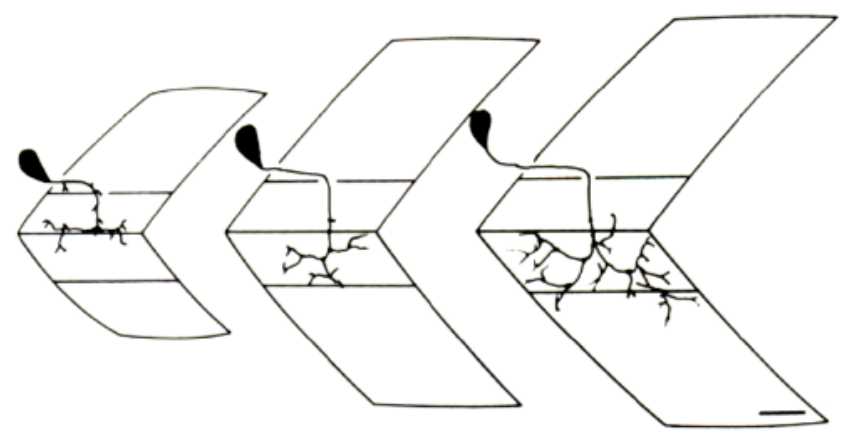

Figure 6. RoP arborizes in its normal cell-specific territory in the absence of $\mathrm{CaP}, \mathrm{MiP}$, and VaP. For the cell illustrated here, $\mathrm{CaP}$ and $\mathrm{MiP}$ were ablated in a segment in which $\mathrm{VaP}$ was not present. $\mathrm{RoP}$ is shown at 22,48 , and $72 \mathrm{~h}$. Scale bar, $20 \mu \mathrm{m}$. selection of the RoP growth cone through $72 \mathrm{~h}$. In all 5 cases, we found that the RoP growth cone selected its normal cellspecific pathway in the absence of all other primary motoneurons from the same hemisegment (Fig. 6). We conclude that, like MiP, RoP can select the pathway that leads to its cell-specific territory even when it is the only primary motoneuron in a hemisegment.

\section{Outgrowth of $\mathrm{CaP}$}

To test the possibility that pathway selection by the CaP growth cone might be affected by the absence of MiP or RoP, we ablated both MiP and RoP in hemisegments in which VaP was absent and examined $\mathrm{CaP}$ through $72 \mathrm{~h}$. In 4 out of 4 cases, the $\mathrm{CaP}$ arborization pattern was normal at $72 \mathrm{~h}$ following MiP and RoP ablation (cf. Figs. 7 and 2). Thus, in the absence of all other primary motoneurons in the same hemisegment, $\mathrm{CaP}$ did not extend a growth cone along the cell-specific pathways of the other primary motoneurons.

\section{Discussion}

In the zebrafish embryo, individual primary motoneurons appear to act independently of one another during axonal outgrowth and pathway selection. We have shown that the growth cone of each primary motoneuron has an autonomous ability to leave the spinal cord at the appropriate place and pioneer the common pathway to the horizontal septum. The CaP growth

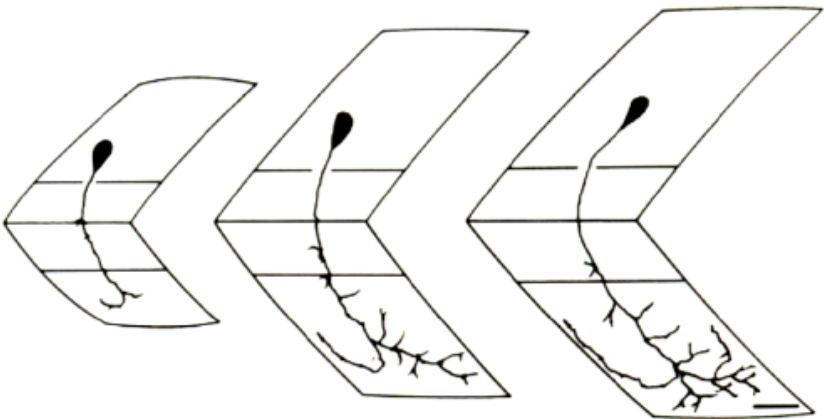

Figure 7. CaP arborizes in its normal cell-specific territory in the absence of MiP and RoP. For the cell illustrated here, MiP and RoP were ablated in a segment in which $\mathrm{VaP}$ was not present, and the CaP outgrowth observed at 22,48 , and $72 \mathrm{~h}$. Scale bar, $20 \mu \mathrm{m}$. 
cone exits the spinal cord first and pioneers the common pathway, except in segments containing $\mathrm{VaP}$, in which either the $\mathrm{CaP}$ or the VaP growth cone may exit first (Eisen et al., 1990). Previous studies showed that in the absence of CaP, both the MiP (Eisen et al., 1989) and the VaP (Eisen et al., 1990) growth cones can pioneer the common pathway. In this paper, we demonstrated that, in the absence of all the other primary motoneurons, the RoP growth cone could exit the spinal cord and pioneer the common pathway as well. Thus, all 4 of the identified primary motoneurons can pioneer the common pathway. This result is consistent with the idea that there is "general" guidance information (Lewis et al., 1983; Bixby et a!., 1987) along the common pathway that is accessible to the growth cones of all 4 primary motoneurons.

We originally hypothesized (Eisen et al., 1989) that interactions among motor growth cones and axons could be important for generating stereotypical arborization patterns. The present study shows that, in the absence of other primary motoneurons, each primary motor growth cone selects its normal cell-specific pathway and grows to its functionally appropriate muscle target. This strongly suggests that interactions among the motoneuronal processes are not required for selection of the appropriate cell-specific pathway. However, our experiments do not rule out the possibility that interactions among primary motoneurons are employed during pathway selection in concert with other pathway cues. Therefore, in the absence of other types of cues, interactions between primary motoneurons might be important for pathway selection.

A number of mechanisms might account for cell-specific pathway choice by the primary motor growth cones. For instance, (1) there may be "general" cues that are accessible to the growth cones of all primary motoneurons but are expressed on particular pathways only at the time that corresponds to the arrival of the growth cone of the appropriate motoneuron; (2) there may be cell-specific signals that guide individual growth cones to appropriate target regions, including signals localized to specific "sorting" regions where growth cones select divergent pathways. Of course, there is no reason to assume that these mechanisms are mutually exclusive.

\section{Timing}

Our studies suggest that growth cones do not compete for pathways based on their sequence of arrival at the horizontal septum. However, the time of arrival of a growth cone at the horizontal septum may determine which pathway that growth cone selects. General guidance cues, available to any of the primary motor growth cones, might be expressed by the cell-specific pathways only at the specific developmental stage that coincides with the arrival time of the appropriate growth cone at the horizontal septum. For example, the pathway leading to the dorsal muscle might only be available after the MiP growth cone reaches the horizontal septum, but before the RoP growth cones reaches that point. This model could be tested by heterochronic transplantation of primary motoneurons. One piece of evidence that argues against this model is that either the $\mathrm{CaP}$ or the $\mathrm{VaP}$ growth cone can reach the horizontal septum first, and yet this does not appear to influence the pathways selected by the CaP and VaP growth cones, at least through $24 \mathrm{~h}$ (Eisen et al., 1990). However, since VaP differs from the other primary motoneurons in a number of significant features (Eisen et al., 1990), it is possible that timing might influence MiP and RoP in a way that is not important for VaP.

\section{Cell-specific signals}

Another mechanism consistent with our data is a distribution of "cell-specific" signals in the environment that direct growth cones to grow to appropriate muscle targets as described in the "labeled pathways" hypothesis proposed by Raper et al. (1983; see also Kuwada, 1986; Bastiani et al., 1987; Dodd et al., 1988). Such a model predicts the presence of distinct guidance cues on each cell-specific pathway and is consistent with our observations that individual growth cones do not appear to recognize unoccupied, inappropriate pathways.

Our data are also consistent with the possibility that growth cones receive guidance information from contact with the choicepoint region at the horizontal septum. Motoneurons that innervate the chick hindlimb sort out and choose cell-specific pathways in the nerve plexus region adjoining the spinal cord (Lance-Jones and Landmesser, $1981 \mathrm{a}, \mathrm{b}$; Tosney and Landmesser, 1985; Landmesser, 1988). Ablation of tissue distal to the plexus does not affect sorting (Tosney and Landmesser, 1984), suggesting that the motoneurons are specified with respect to their target and respond to specific guidance cues that reside within the vicinity of the plexus. In the zebrafish embryo, the region around the horizontal septum appears to serve as a "sorting region" for the primary motor growth cones. Two pieces of evidence support this idea. First, prior to selecting cell-specific pathways, all of the primary motor growth cones extend to the horizontal septum and pause. This is especially striking in the case of MiP, which innervates the dorsal muscle. After the MiP growth cone pauses at the horizontal septum, it sprouts a dorsal collateral and retracts the original axon from the horizontal septum. This suggests that information residing in the region of the horizontal septum may be required for MiP to elaborate the dorsal collateral that extends to MiP's cell-specific muscle territory. Second, the muscle fibers adjacent to the horizontal septum show specializations not evident in other muscle fibers in the hemisegment (A. Felsenfeld and M. Curry, unpublished observations). The importance of the horizontal septum region is currently being tested by deleting the specialized muscle fibers.

While we have demonstrated that interactions among the primary motoneurons are not necessary for selection of appropriate pathways, the observation that the ventral process of MiP remains at the horizontal septum for a significantly longer period of time when $\mathrm{CaP}$ is ablated suggests that the $\mathrm{CaP}$ and $\mathrm{MiP}$ neurites might interact. Such an interaction would not be required for cell-specific pathway selection, but might play a role in some as yet unidentified process during motoneuronal development. It is clear that during pathfinding the motor growth cones may use other mechanisms in addition to, or instead of, those suggested here. The accessibility of this system to manipulation should allow us to determine which mechanisms are actually responsible for accurate pathway selection.

\section{References}

Bastiani, M. J., and C. S. Goodman (1984) The first growth cones in the central nervous system of the grasshopper embryo. In Cellular and Molecular Biology of Neuronal Development, I. B. Black, ed., pp. 63-84, Plenum, New York.

Bastiani, M. J., A. L. Harrelson, P. M. Snow, and C.S. Goodman (1987) Expression of fasciclin I and II glycoproteins on subsets of axon pathways during neuronal development in grasshopper. Ccll 48: 745-755.

Berlot, J., and C. S. Goodman (1984) Guidance of peripheral pioneer neurons in the grasshopper: Adhesive hierarchy of epithelial and neuronal surfaces. Science 223: 493-495. 
Bixby, J. L., R. S. Pratt, J. Lilien, and L. F. Reichardt (1987) Neurite outgrowth on muscle cell surfaces involves extracellular matrix receptors as well as $\mathrm{Ca}^{2+}$-dependent and -independent cell adhesion molecules. Proc. Natl. Acad. Sci. USA 84: 2555-2559.

Caudy, M., and D. Bentley (1986a) Pioneer growth cone morphologies reveal proximal increases in substrate affinity within leg segments of grasshopper embryos. J. Neurosci. 6: 364-379.

Caudy, M., and D. Bentley (1986b) Pioneer growth cones steering along a series of neuronal and non-neuronal cues of different affinities. J. Neurosci. 6: 1781-1795.

Davics, A. J. (1987) Molecular and cellular aspects of patterning sensory neurone connections in the vertebrate nervous system. Development 101: 185-208.

Dodd, J., S. B. Morton, D. Karagogeos, M. Yamamoto, and T. M. Jessell (1988) Spatial regulation of axonal glycoprotein expression on subsets of embryonic spinal neurons. Neuron 1 : 105-116.

Eisen, J. S., P. Z. Myers, and M. Westerfield (1986) Pathway selection by growth cones of identified motoneurons in live zebrafish embryos. Nature 320: 269-271.

Eisen, J. S., S. H. Pike, and B. Debu (1989) The growth cones of identified motoneurons in embryonic zebrafish select appropriate pathways in the absence of specific cellular interactions. Neuron 2: 1097-1104.

Eisen, J. S., S. H. Pike, and B. Romancier (1990) An identified neuron with variable fates in embryonic zebrafish. J. Neurosci. 10: 34-43.

Goodman, C. S., J. A. Raper, R. K. Ho, and S. Chang (1982) Pathfinding by neuronal growth cones in grasshopper embryos. In Developmental Order: Its Origin and Regulation, S. Subtelny and P. B. Green, eds., pp. 275-316, Liss, New York.

Hanneman, E., and M. Westerfield (1989) Early expression of acetylcholinesterase activity in functionally distinct neurons of the zebrafish. J. Comp. Neurol. (in press).

Honig, M., and R. Hume (1986) Fluorescent carbocyanine dyes allow living neurons of identified origin to be studied in long-term cultures. J. Cell Biol. 103: 171-187.

Kapfhammer, J. P., and J. A. Raper (1987) Interactions between growth cones and neurites growing from different neural tissues in culture. J. Neurosci. 7: 1595-1600.

Kimmel, C. B., and R. D. Law (1985) Cell lineage of zebrafish blas- tomeres. I. Cleavage pattern and cytoplasmic bridges between cells. Dev. Biol. 108: 78-85.

Kuwada, J. (1986) Cell recognition by neuronal growth cones in a simple vertebrate embryo. Science 233: 740-746.

Lance-Jones, C., and L. Landmesser (1981a) Pathway selection by chick lumbosacral motoneurons during normal development. Proc. R. Soc. London [Biol.] 214: 1-18.

Lance-Jones, C., and L. Landmesser (1981b) Pathway selection by embryonic chick motoneurons in an experimentally altered environment. Proc. R. Soc. London [Biol.] 214: 19-52.

Landmesser, L. T. (1980) The generation of ncuromuscular spccificity. Annu. Rev. Neurosci. 3: 279.

Landmesser, L. R. (1988) Peripheral guidance cues and the formation of specific motor projections in the chick. In From Message to Mind, S. S. Easter, K. F. Barald, and B. M. Carlson, eds., pp. 121-133, Sinauer, Sunderland, MA.

Lewis, J., L. Al-Ghaith, G. Swanson, and A. Khan (1983) The control of axon outgrowth in the developing chick wing. In Limb Development and Regeneration. J. F. Fallon and A. I. Caplan, eds., pp. 195-205, Liss, New York.

Myers, P. Z. (1985) Spinal motoneurons of the larval zebrafish. J. Comp. Neurol. 236: 555-561.

Myers, P. Z., J. S. Eisen, and M. Westerfield (1986) Development and axonal outgrowth of identified motoneurons in the zebrafish. J. Neurosci. 6: 2278-2289.

Pike, S., and J. S. Eisen (1988) Interactions between identified motoneurons during pathway selection in zebrafish embryos. Soc. Neurosci. Abstr. 14: 870.

Raper, J. A., M. Bastiani, and C. S. Goodman (1983) Pathfinding by neuronal growth cones in grasshopper embryos. II. Selective fasciculation onto specific axonal pathways. J. Neurosci. 3: $31-41$.

Tosney, K. W., and L. T. Landmesser (1984) Pattern and specificity of axonal outgrowth following varying degrees of chick limb bud ablation. J. Neurosci. 4: 2518-2527.

Tosney, K. W., and L. T. Landmesser (1985) Specificity of motoneuron growth cone outgrowth in the chick limb. J. Neurosci. 6: 2336-2344.

Westerfield, M., J. McMurray, and J. S. Eisen (1986) Identified motoneurons and their innervation of axial muscles in the zebrafish. J. Ncurosci. 6: 2267-2277. 